\title{
Changing the method of consent to increase the numbers of \\ cadaveric donors in Saudi Arabia: the autonomy paradox
}

\section{[version 1; peer review: 2 not approved]}

\author{
Deema AL Shawan (iD), Faisal Albagmi (iD)2, Heba AINujaidi (iD) \\ ${ }^{1}$ Public Health, Imam Abdulrahman Bin Faisal University, Dammam, Saudi Arabia \\ ${ }^{2}$ Department of Physical Therapy, Imam Abdulrahman Bin Faisal University, Dammam, Saudi Arabia
}

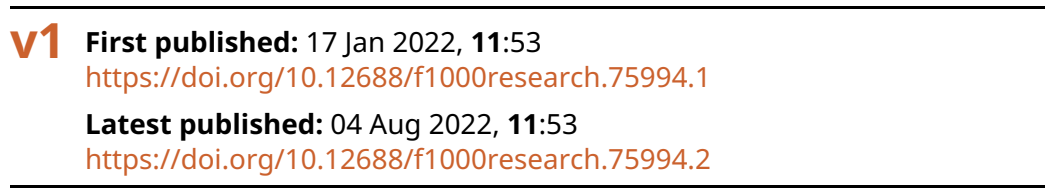

\section{Abstract}

Background: In Saudi Arabia, the gap between the demand for and availability of organs persists, with a total of 13,731 patients on the waiting list in 2019. Family refusal is a major obstacle limiting donation since their consent must be obtained prior to the retrieval of organs. The cause of family refusal is mainly due to their lack of knowledge of their loved ones' wish to become a donor. This paper aimed to compare three systems of obtaining consent in terms of effectiveness, respect for autonomy, and the cultural role of families in Saudi Arabia to ensure feasibility and effectiveness in increasing the number of donors.

Policy alternatives and implications: The consent systems include informed consent, presumed consent, and mandated choice. The mandated choice policy might be the optimal solution since it is the most likely to balance the respect for individual autonomy and the cultural role of families in Saudi Arabia.

Conclusions and recommendations: Mandated choice ensures the respect of autonomy while influencing the next of kin's decision to donate the organs. Additionally, a recommendation to decision makers is to utilize the Tawakkalna app to send alerts to the next of kin when a user registers as a donor with the users' consent. Moreover, more research should be dedicated to investigating the Saudi public's current culture and perceptions towards organ donation to ensure feasibility.

\section{Keywords}

Organ, donation, transplantation, Tawakkalna, consent, cadaveric, donors, family consent

Open Peer Review
Approval Status
version 2
(revision)
04 Aug 2022
version 1
17 Jan 2022
......................................................................
1. Alberto Molina-Pérez
Research Council, Cordoba, Spanish National
2. James Stacey Taylor, The College of New
Jersey, Ewing, USA
Any reports and responses or comments on the
article can be found at the end of the article.


This article is included in the Sociology of

Health gateway.

Corresponding author: Deema AL Shawan (dshawan@iau.edu.sa)

Author roles: AL Shawan D: Conceptualization, Formal Analysis, Investigation, Resources, Supervision, Visualization, Writing - Original Draft Preparation, Writing - Review \& Editing; Albagmi F: Conceptualization, Resources, Writing - Review \& Editing; AINujaidi H:

Resources, Visualization, Writing - Review \& Editing

Competing interests: No competing interests were disclosed.

Grant information: The author(s) declared that no grants were involved in supporting this work.

Copyright: @ 2022 AL Shawan D et al. This is an open access article distributed under the terms of the Creative Commons Attribution License, which permits unrestricted use, distribution, and reproduction in any medium, provided the original work is properly cited.

How to cite this article: AL Shawan D, Albagmi F and AINujaidi $H$. Changing the method of consent to increase the numbers of cadaveric donors in Saudi Arabia: the autonomy paradox [version 1; peer review: 2 not approved] F1000Research 2022, 11:53 https://doi.org/10.12688/f1000research.75994.1

First published: 17 Jan 2022, 11:53 https://doi.org/10.12688/f1000research.75994.1 


\section{Introduction}

Organ transplantation is one of the major advances of modern medicine: it saves and enhances the quality of the lives of patients with organ failure. Nonetheless, this achievement is hindered by organ shortages worldwide. The gap between the supply and demand of organs is also evident in Saudi Arabia, one of the first Arab countries with an organized organ procurement system (Shaheen \& Souqiyyeh, 2004). Despite Saudi Arabia's efforts to increase the number of donors within the past three decades, the shortage persists, with a total of 13,731 patients who remain on the waiting list in 2019 (Saudi Center for Organ Transplantation, 2019). The consequences of organ shortage are not limited to the decreased quality and the loss of patients' lives on waiting lists. This public health crisis also has a significant economic impact due to the government funding $48 \%$ of dialysis facilities in the Kingdom (Al-Dossary et al., 2013).

The organ procurement system in Saudi Arabia is regulated by The Saudi Center for Organ Transplantation (SCOT), which is a governmental agency. The center was created after the Islamic resolution in 1982, which marked a turning point in the country's history by permitting organ and tissue donation. The main responsibilities of SCOT include allocating organs for transplantation, conducting annual statistics, raising public awareness, and developing policies to ensure the ethical retrieval and transplantation of organs. Additionally, SCOT acts as a referral center for Gulf Cooperation Council (GCC) countries and Spain (Al-Dossary et al., 2013).

There are two main types of donors: 1) living-related and nonrelated; and 2) cadaveric donors. Cadaveric donors are the main source of organs in Saudi Arabia; therefore, the shortage might not be resolved by utilizing living donors (Alsebayel et al., 2004). The current process for organ procurement in Saudi Arabia requires the intensive care unit (ICU) staff, or in some cases, the emergency room (ER) or the surgical unit staff, to identify possible cadaveric donors. A nurse assigned by SCOT notifies the center about the potential deceased donor and documents it. Then, clinical examinations are performed to ensure that the donor meets the brain death criteria developed by SCOT and the Saudi Ministry of Health (MOH). After the process is complete and the declaration of brain death is officially obtained, the ICU physician is required to approach the donor's family to obtain written consent using an official consent form (Al-Dossary et al., 2013).

Possible obstacles that hinder this process include health providers not reporting cases of possible cadaveric donors, family refusal to consent, medical causes, and lack of awareness on the part of hospital staff in donor hospitals. Family refusal is a major obstacle limiting donation, with only $33 \%$ of approached families consenting to donate their loved one's organs in 2019 (Saudi Center for Organ Transplantation, 2019). Lack of knowledge of the potential donors' next of kin of their loved ones' wishes to donate their organs is one of the main reasons for the families' refusal to consent (Palmer, 2012). To overcome this issue, improvements should be made in documenting potential donors' consent in organ donation registries.

There are three known methods of consent when registering to become a donor upon death: informed consent (opt-in system), mandated choice and presumed consent (opt-out system) (Al-Dossary et al., 2013). This paper aims to analyze the different types of consent systems to address the issue of the high rate of family refusal. The study offers some important insights that will aid decision-makers in selecting an alternative that is more likely to reduce the shortage of organs.

\section{Policy alternatives and implications}

Informed consent system (status quo)

The current method of registering donors in Saudi Arabia is an opt-in system where individuals voluntarily state that they wish to become donors upon death. Originally, there was no organ donation registry in the Kingdom, and donors were encouraged to fill out donor cards issued by SCOT to document their wishes to be donors upon death. The lack of a registry made it difficult to identify the deceased decision to notify the family unless the donor card was found at the time of death. It is important to note that, under the current policy, families still have the right to veto that decision despite their loved one's consent to become a donor (Al-Dossary et al., 2013).

Donor cards were recently replaced with online registration on SCOT's website as well as the Tawakkalna app. The app was developed by the Saudi Data and Artificial Intelligence Authority (SDAIA) to display the users' coronavirus disease 2019 (COVID-19) status upon entry to public places following government regulations. Due to most of the Saudi public downloading the app, SCOT collaborated with SDAIA to allow users to register to become donors through it (Yosri, 2021).

In terms of effectiveness, there was a drastic increase of registered donors after the utilization of Tawakkalna. According to a news article, the number of registered donors increased from 20,000 to 200,000 , which is a $115 \%$ increase after the launch of the donor registration feature. This spike in the number of registered donors was attributed to the app's ease of use and accessibility (Alsharq Alawsat, 2021). 
Nevertheless, when it comes to an opt-in system, there is still a likelihood that willing donors may not register. This issue is prevalent in several countries around the world with a similar opt-in system. For instance, in the United States, 95\% of adults support organ donation, while merely $54 \%$ are registered as donors (Anderson, 2017). There are limited studies on this obstacle in Saudi Arabia; nonetheless, one study investigated the willingness of Saudi University students to become donors upon death. According to the results, about $70 \%$ of participants are willing to become donors; however, none of them carried donor cards that were the enrollment method for the study (Al-Ghanim, 2009).

As for ethical considerations, the current opt-in system respects an individual's autonomy. According to Immanuel Kant, undermining a person's autonomy is to treat that person as a mere means to an end without regard for the individual's own goals. Based on Kant's theory, organs from a deceased individual should not be harvested if the person's wish was not to be a donor, even if it intends to save others (Johnson \& Cureton, 2021).

Under informed consent in Saudi Arabia, individuals might still "exercise their autonomy in choosing to accept an institution, tradition, or community that they view as a legitimate source of direction" (Holm, 2002). Therefore, an organ consent policy needs to ensure that those views are respected.

\section{Presumed consent system}

In a presumed consent system, an individual is assumed to be a donor unless they specifically opt-out. There are two variations of this policy: a hard opt-out and a soft opt-out. In a hard opt-out approach, the families of cadaveric donors are not consulted before retrieving the donated organs. In contrast, in a soft opt-out policy, the families' wishes are considered (Al-Dossary et al., 2013).

Several countries around the world have adopted variations of the presumed consent system with different degrees of success. For instance, after adopting a hard opt-out policy in Austria, the rate of donations quadrupled within eight years (Zink et al., 2005). On the other hand, a soft approach to the policy did not impact donation rates in Spain, which indicates that a hard opt-out policy could be more effective. Despite the success and cost-effectiveness of hard opt-out policies, there are still some concerns, such as increasing the public's mistrust and the risk of undermining autonomy (Bramhall, 2011).

Applying a hard presumed consent policy in the context of Saudi Arabia might be unfeasible due to ethical considerations pertaining to the role of families. In many cases, the family trumps an individuals' autonomy" (Al-Shahri, 2002). Therefore, it may be culturally insensitive to implement a hard presumed consent system that disregards the wishes of the next of kin completely, which could risk public acceptance. Additionally, a presumed consent system was found to be the least favored by the Saudi public. One of the causes of this disfavoring was the Islamic belief that a good deed must be done with intent by the individual, which may not be the case in a system that makes you a donor by default. This belief may lead to the public rejecting even a softer presumed consent system as well (Hammami et al., 2012).

\section{Mandated choice system}

Another possible solution is to replace the current policy with a mandated choice system, where citizens are required to either opt-in or opt-out of becoming organ donors. This system can be implemented in Saudi Arabia by utilizing the preexisting organ donation registration feature on the Tawakkalna app. Currently, the app offers the option to sign up to register as a donor voluntarily; nevertheless, users can unknowingly leave it blank. By implementing a mandated choice system, the app can require individuals to fill out their choice along with the rest of their medical information.

This alternative could increase the number of registered donors by ensuring that willing donors register their wishes and inform their families before death. According to a study conducted in Saudi Arabia in 2018, most participants support organ donation, but merely $2.3 \%$ volunteered to carry organ donation cards to indicate their wishes to become donors (Alnasyan et al., 2019). Therefore, this intervention could address the issue of willing donors neglecting to document their decision.

There is sparse evidence on the effectiveness of a mandated choice system in increasing the number of registered donors. However, the limited available research from other countries indicates the likelihood of the success of this system compared to informed and presumed consent. For instance, a study in the Netherlands, a country that adopted a mandated choice, concluded that this system generated more registered donors than both informed and presumed consent systems (Van Dalen \& Henkens, 2014).

As for ethical considerations, a mandated choice system makes the two choices readily available; it increases a person's likelihood of making an autonomous choice and encourages self-determination. In other words, this system eliminates 
the presumption involved, and each individual could explicitly state their wishes prior to death. Furthermore, this consent mechanism can further cultivate public acceptance due to its respect for families' roles. Additionally, due to the accessibility of the app, individuals can opt-out at any time, which could further ensure the next of kin that this was their loved one's wish with more confidence (Steffel et al., 2019).

Mandated choice is more likely to ensure that families do not go against their loved one's wishes unknowingly by donating their organs. Individuals are less likely to opt-out while they are alive if they have not been given the option of doing so, which may cause their families to possibly give consent after their deaths. Experimental studies suggest that "individuals have more confidence that they know someone else's donation preferences under mandated choice systems than with presumed consent systems" (Steffel et al., 2019, p.77).

\title{
Actionable recommendations
}

A policy of mandated choice eliminates the presumption involved since an individual can explicitly state their wish to be a donor before death. Therefore, this policy is more likely to be feasible in the Kingdom due to its respect for the cultural role of the family as well.

In addition to changing the method of obtaining consent, there are several other recommendations to maximize the benefits of implementing a mandated choice system.

The Tawakkalna App could be modified to send alerts to notify the next of kin once a user selects their donation decision with the users' permission. Additionally, the users can be asked why they chose to opt-out of donation to investigate the underlying factors influencing donation registration rates.

Decision-makers should invest in more research dedicated to assessing the feasibility of implementing a new consent system. In the case of mandated choice, analyzing the effectiveness of this policy in other countries may not be sufficient evidence. A deep understanding of the current Saudi context, including the public's beliefs, social attitudes, and perceptions, is crucial to predicting the success and cultivating public acceptance for this policy (Al-Khader et al., 2003).

\section{Conclusion}

One of the main obstacles in obtaining family consent in Saudi Arabia is family refusal. The method of obtaining consent could influence the next of kin's decision, especially if it accurately reflects the donor's decision. Due to the cultural role of families in Saudi Arabia, obtaining consent must carefully balance respect for individual autonomy and the role of families. For that reason, mandated choice may be the best alternative to address this moral dilemma.

\section{Data availability}

No data are associated with this article.

\author{
References \\ Al-Dossary S, Al-Dulaijan N, Al-Mansour S, et al.: Organ Donation and \\ Transplantation: Processes, Registries, Consent, and Restrictions in \\ Saudi Arabia [Chapter].Handbook of Research on ICTs for Human-Centered \\ Healthcare and Social Care Services. IGI Global; 2013. \\ Publisher Full Text \\ Al-Ghanim SA: The willingness toward deceased organ \\ donation among university students. Implications \\ for health education in Saudi Arabia. Saudi Med. J. 2009; 30(10): \\ 1340-1345. \\ PubMed Abstract \\ Al-Khader AA, Shaheen FaM, Al-Jondeby MS: Important social factors \\ that affect organ transplantation in Islamic countries. Experimental \\ and Clinical Transplantation: Official Journal of the Middle East Society for \\ Organ Transplantation. 2003; 1(2): 96-101. \\ PubMed Abstract \\ Alnasyan AY, Aldihan KA, Albassam AA, et al.: How informed are the Saudi \\ public about the value of organ donation: A community-based cross- \\ sectional study. Saudi J. Kidney Dis. Transpl. 2019; 30(6): 1236. \\ PubMed Abstract | Publisher Full Text \\ Alsebayel $\mathrm{M}$, Al-Enazi A, Al-Sofayan $\mathrm{M}$, et al.: Improving organ donation in \\ Central Saudi Arabia. Saudi Med. J. 2004; 25: 1366-1368. \\ Al-Shahri M: Culturally Sensitive Caring for Saudi Patients. Journal of \\ Transcultural Nursing: Official Journal of the Transcultural Nursing Society/ \\ Transcultural Nursing Society. 2002; 13: 133-138. \\ PubMed Abstract | Publisher Full Text \\ Alsharq Alawsat: The number of organ donors in Saudi Arabia \\ increased to $115 \%$ within a month. Alsharq Alawsat. 2021. \\ Reference Source \\ Anderson A: Organ donation: 10 minutes. 22 people. 54 percent. \\ ScienceDaily; 2017. \\ Reference Source \\ Bramhall S: Presumed consent for organ donation: A case against. \\ Ann. R. Coll. Surg. Engl. 2011; 93(4): 270-272. \\ Publisher Full Text \\ Hammami MM, Abdulhameed HM, Concepcion KA, et al.: Consenting \\ options for posthumous organ donation: Presumed consent and \\ incentives are not favored. BMC Med. Ethics. 2012; 13(1): 32. \\ PubMed Abstract | Publisher Full Text \\ Holm S: Principles of Biomedical Ethics, 5th edn.: Beauchamp T L, \\ Childress J F. Oxford University Press, 2001, £19.95, pp 454. ISBN \\ 0-19-514332-9. J. Med. Ethics. 2002; 28(5): 332-332. \\ Publisher Full Text
}


Johnson R, Cureton A: Kant's Moral Philosophy. Zalta EN, editor. The Stanford Encyclopedia of Philosophy (Spring 2021). Metaphysics Research Lab, Stanford University; 2021.

Reference Source

Palmer M: The role of families in organ donation: International evidence review. GOV.WALES; 2012.

Reference Source

Saudi Center for Organ Transplantaion: Annual Report for Organ

Transplantation in Kingdom of Saudi Arabia. 2019.

Reference Source

Shaheen FAM, Souqiyyeh MZ: Increasing organ donation rates from Muslim donors: Lessons from a successful model. Transplant. Proc.

2004; 36(7): 1878-1880.

PubMed Abstract | Publisher Full Text
Steffel M, Williams EF, Tannenbaum D: Does changing defaults save lives? Effects of presumed consent organ donation policies. Behav. Sci. Policy. 2019; 5(1): 68-88.

Publisher Full Text

van Dalen HP, Henkens $\mathrm{K}$ : Comparing the effects of defaults in organ donation systems. Soc. Sci. Med. 2014; 106: 137-142.

PubMed Abstract | Publisher Full Text

Yosri: Saudi's Tawakkalna launches registration service for organ

donation. 2021

Reference Source

Zink S, Zeehandelaar R, Wertlieb S: Presumed vs Expressed Consent in the US and Internationally. AMA J. Ethics. 2005; 7(9): 610-614.

Publisher Full Text 


\section{Open Peer Review}

\section{Current Peer Review Status: $\mathrm{X} X$}

\section{Version 1}

Reviewer Report 20 June 2022

https://doi.org/10.5256/f1000research.79943.r136403

(C) 2022 Taylor J. This is an open access peer review report distributed under the terms of the Creative Commons Attribution License, which permits unrestricted use, distribution, and reproduction in any medium, provided the original work is properly cited.

\section{James Stacey Taylor}

Department of Philosophy, The College of New Jersey, Ewing, NJ, USA

This is a nicely written paper that argues in favor of using mandated choice to increase the availability of transplant organs in Saudi Arabia. While it does not cover any new ground in its ethical discussion it provides helpful information about the ways in which new technology might be used to enhance organ procurement. However, it suffers from significant empirical and theoretical weaknesses that preclude its indexing as it stands, including inaccurate data, claims that are insufficiently supported by evidence and a poor grounding in philosophical ethics and action theory. I have provided an overview of these issues below.

\section{Issue 1:}

"According to a news article, the number of registered donors increased from 20,000 to 200,000, which is a $115 \%$ increase after the launch of the donor registration feature."

Three points are worth noting here:

1. Is there a better source for these figures than a news article? Have the authors examined the original source on which this news article was based? How accurate is this claim?

2. The increase from 20,000 to 200,000 is not " $115 \%$ " as the authors claim. This needs to be corrected.

3. When the authors write "...115\% increase after the launch of the donor registration feature" do they mean that this $115 \%$ increase was immediate after the launch, and then numbers further increased, or do they mean to claim that the increase to 200,000 occurred in the total time after the launch? (The former construal would be compatible with there being an initial increase of $115 \%$ and then an greater increase subsequently.)

\section{Issue 2:}

"As for ethical considerations, the current opt-in system respects an individual's autonomy. According to Immanuel Kant, undermining a person's autonomy is to treat that person as a mere 
means to an end without regard for the individual's own goals. Based on Kant's theory, organs from a deceased individual should not be harvested if the person's wish was not to be a donor, even if it intends to save others."

There are three points that should be made with respect to the claims in this sentence.

1. The authors should distinguish between personal autonomy and Kantian autonomy. On a theory of personal autonomy a person is autonomous with respect to her desires and actions if they flow from her motivational set in a way that ensures that they originate from her, rather than from elsewhere (where the requirements for what counts as originating from her are spelled out in the theory of personal autonomy that one adopts). On a Kantian account of autonomy a person is autonomous if (roughly) she acts out of respect for the moral law. These are distinct accounts of autonomy, and since the former is often of primary interest in discussions of organ procurement the authors would do well to focus on it rather than its Kantian alternative.

2. Why couldn't an opt-out approach to organ procurement also respect a person's (personal) autonomy? The authors should see here Michael Gill's "Presumed Consent, Autonomy, and Organ procurement," Journal of Medicine and Philosophy 29, 1 (2004): 37 - $59^{1}$.

3. Merely claiming that Kant would hold that a person's organs should not be harvested after her death if she did not agree to this is insufficient. The authors need to argue that Kant (or Kantians) are committed to holding that persons have duties to respect the wishes of the dead.

\section{Issue 3:}

The authors should note that the differences in the effectiveness of the Austrian and Spanish systems might also be a product of differing infrastructure that is in place to secure available organs, and not merely the result of their different approaches to opt-out systems. The authors also need to provide better sources for their claims here.

\section{Issue 4:}

"According to a study conducted in Saudi Arabia in 2018, most participants support organ donation..." - What percentage is captured by "most"?

\section{Issue 5:}

"As for ethical considerations, a mandated choice system makes the two choices readily available; it increases a person's likelihood of making an autonomous choice and encourages selfdetermination."

Why does requiring persons to make a choice between two alternatives increase her "...likelihood of making an autonomous choice and encourages self-determination"? Indeed, couldn't requiring that a person choose between two alternatives decrease the degree to which she is autonomous with respect to her relevant choices, insofar as it removes from her the option not to choose - an option which some persons might have preferred? The authors need to do much more to support their claims here, especially since they appear prima facie implausible. 


\section{References}

1. Gill MB: Presumed consent, autonomy, and organ donation.J Med Philos. 2004; 29 (1): 37-59

PubMed Abstract | Publisher Full Text

Does the paper provide a comprehensive overview of the policy and the context of its implementation in a way which is accessible to a general reader?

Partly

Is the discussion on the implications clearly and accurately presented and does it cite the current literature?

No

Are the recommendations made clear, balanced, and justified on the basis of the presented arguments?

Partly

Competing Interests: No competing interests were disclosed.

Reviewer Expertise: The ethics of organ procurement, autonomy theory, and the metaphysics of death.

I confirm that I have read this submission and believe that I have an appropriate level of expertise to state that I do not consider it to be of an acceptable scientific standard, for reasons outlined above.

Author Response 05 Jul 2022

Deema AL Shawan, Imam Abdulrahman Bin Faisal University, Dammam, Saudi Arabia

Dear Professor Taylor,

Thank you for your insightful comments and suggestions. We have incorporated the edits to our manuscript. Additionally, we have a point-by-point response below.

Comment: "According to a news article, the number of registered donors increased from 20,000 to 200,000 , which is a $115 \%$ increase after the launch of the donor registration feature."

"Is there a better source for these figures than a news article? Have the authors examined the original source on which this news article was based? How accurate is this claim?"

When the authors write "...115\% increase after the launch of the donor registration feature" do they mean that this $115 \%$ increase was immediate after the launch, and then numbers further increased, or do they mean to claim that the increase to 200,000 occurred in the total time after the launch? (The former construal would be compatible with there being an initial increase of $115 \%$ and then an greater increase subsequently.) 
Response: This was a error on part of the news article itself, therefore, we have corrected the information and replaced it with a more reliable source.

Comment: "The authors should distinguish between personal autonomy and Kantian autonomy. On a theory of personal autonomy a person is autonomous with respect to her desires and actions if they flow from her motivational set in a way that ensures that they originate from her, rather than from elsewhere (where the requirements for what counts as originating from her are spelled out in the theory of personal autonomy that one adopts). On a Kantian account of autonomy a person is autonomous if (roughly) she acts out of respect for the moral law. These are distinct accounts of autonomy, and since the former is often of primary interest in discussions of organ procurement the authors would do well to focus on it rather than its Kantian alternative.

Response: We thank you for the insightful comment, we agree and we have made the suggested correction to focus on personal autonomy. We made the clarification in the background, analysis sections.

Comment: "Why couldn't an opt-out approach to organ procurement also respect a person's (personal) autonomy? The authors should see here Michael Gill's "Presumed Consent, Autonomy, and Organ procurement," Journal of Medicine and Philosophy 29, 1 (2004): 37 - 591."

Response: Thank you for the insightful comment and sharing this reference. We have incorporated your suggestion into our manuscript and expressed the other potential concerns. For one thing, there is a risk that organs could be removed from bodies of individuals who did not want their organs removed. On the other hand, we do agree with (Gill, 2004) that "it is morally no worse than not removing organs from the bodies of people who did want them removed." However, as stated in the manuscript this method is not favored by the Saudi public due to religious reasons. (Hammami et al., 2012) Which is why we recommended that decision makers support investigating mandated choice as an option, since it could be a balance between the risk of removing organs from individuals who did not wish to be donors and the risk of not harvesting organs from willing donors. The clarification was made in the manuscripts and additional references were added.

Comment: "Merely claiming that Kant would hold that a person's organs should not be harvested after her death if she did not agree to this is insufficient. The authors need to argue that Kant (or Kantians) are committed to holding that persons have duties to respect the wishes of the dead."

Response: We have updated to individual autonomy as recommended in a previous comment and provided further explanations and evidence.

Comment: The authors should note that the differences in the effectiveness of the Austrian and Spanish systems might also be a product of differing infrastructure that is in place to secure available organs, and not merely the result of their different approaches to opt-out systems. The authors also need to provide better sources for their claims here. 
Response: The sources were updated accordingly.

Comment: "According to a study conducted in Saudi Arabia in 2018, most participants support organ donation..." - What percentage is captured by "most"?

Response: The percentage was added as suggested.

Comment: "Why does requiring persons to make a choice between two alternatives increase her "...likelihood of making an autonomous choice and encourages selfdetermination"? Indeed, couldn't requiring that a person choose between two alternatives decrease the degree to which she is autonomous with respect to her relevant choices, insofar as it removes from her the option not to choose - an option which some persons might have preferred? The authors need to do much more to support their claims here, especially since they appear prima facie implausible."

Response: That is a valid argument, however, we took into consideration that religion and culture play an important role in determining how autonomy is perceived. We made this recommendation considering the applicability to Saudi Arabia's culture role of families, religion, public acceptance. Due to religious beliefs for organ donation to be a considered good deed there must be intent by the individual to be a donor. Due to this belief, clearly knowing the next of kin wish could influence the families to approve of the donation. Furthermore, according to a study we have added to the manuscript, mandated choice was the most favored option by the public. Lastly, due to the accessibility of the App, users have the option to opt-out at any moment.

We look forward to hearing back from you and please let us know if you have any further inquiries and comments you may have.

Sincerely,

Dr. Deema S. Al Shawan

Competing Interests: No competing interests were disclosed.

Reviewer Report 20 January 2022

https://doi.org/10.5256/f1000research.79943.r120048

(C) 2022 Molina-Pérez A. This is an open access peer review report distributed under the terms of the Creative Commons Attribution License, which permits unrestricted use, distribution, and reproduction in any medium, provided the original work is properly cited.

\section{Alberto Molina-Pérez}

Institute for Advanced Social Studies, Spanish National Research Council, Cordoba, Spain 
The article first describes the organ donation system in Saudi Arabia and identifies the high rate of family opposition as one major obstacle to increasing cadaveric organ donation rates in the country. Then, the article presents the three main consent policies: opt-in (explicit consent), optout (presumed consent), and mandated choice, advocating for the latter one as the best alternative in the context of Saudi Arabia.

Overall, the article is well written and provides a clear and accessible overview of the consent policy alternatives. One interesting point mentioned in the article is the use of the Tawakkalna app as a means of registration of individual preferences about organ donation. However, the article lacks depth in its analysis and suffers from some mistakes and inaccuracies that need to be addressed.

\section{"Does the paper provide a comprehensive overview of the policy and the context of its implementation in a way which is accessible to a general reader?"}

Only partly. The overview is accessible to a general reader but it is not comprehensive and it lacks depth in its analysis. Also, its main hypothesis is based on insufficient evidence.

For instance, after mentioning that only 33\% of approached families authorised in 2019 the retrieval of organs from their loved ones, the article claims that the relatives' lack of knowledge of the deceased's wishes as one of the main reasons for the families' refusal. [By the way, the wording of the sentence beginning "Lack of knowledge of the potential donor..." should be revised.] This second claim is based on Palmer 2012. Although this reference appears to be a good review of the literature, it has not been peer-reviewed. In addition, it is also relatively outdated (meaning that other reviews have been conducted more recently) and the studies reviewed were conducted mostly in English speaking Western countries: the United States, the United Kingdom, Australia, which means that their conclusions may not necessarily be extensible to other cultural contexts such as Saudi Arabia. In other words, although it may be true that lack of knowledge by the family is, in these countries, one of the main reasons for their refusal, there is no guarantee that the same conclusion holds in other countries, especially when these countries (e.g. Saudi Arabia) have a different social organization, religion, and cultural background.

Since the argument of the article is based on the claim that family refusals are mainly caused by the family's lack of knowledge of the potential donor wishes (which could be addressed, according to the authors, by a mandated choice policy), stronger evidence is needed to support this claim, especially in the context of Saudi Arabia. In other words, authors should provide more updated and compelling evidence that this claim is true-or, at the very least, that it may be true in their country-before proposing a policy to address it.

There is a rich and vast literature of empirical studies on the factors of family decision-making and willingness/refusal to donate that are contemporary or posterior to Palmer 2012. Here are some peer-reviewed literature reviews I am aware of, including some systematic reviews:

Kentish-Barnes N, Siminoff LA, Walker W, Urbanski M, Charpentier J, Thuong M, et al. A narrative review of family members' experience of organ donation request after brain death in the critical care setting. Intensive Care Med 2019;45:331-42.1

Miller C, Breakwell R. What factors influence a family's decision to agree to organ donation? A critical literature review. London Journal of Primary Care 2018;10:103-7. ${ }^{2}$

Makmor T, Abdillah N, NurulHuda Ms, Raja Noriza RA, Roza Hazli Z. Family Decision-Making 
About Organ Donation: A Systematic Review. JUMMEC 2015;18:1-4. ${ }^{3}$

Ralph A, Chapman JR, Gillis J, Craig JC, Butow P, Howard K, et al. Family Perspectives on Deceased Organ Donation: Thematic Synthesis of Qualitative Studies. American Journal of Transplantation 2014;14:923-35. ${ }^{4}$

Walker W, Broderick A, Sque M. Factors Influencing Bereaved Families' Decisions About Organ Donation: An Integrative Literature Review. West J Nurs Res 2013;35:1339-59. 5 . de Groot J, Vernooij-Dassen M, Hoedemaekers C, Hoitsma A, Smeets W, van Leeuwen E. Decision making by relatives about brain death organ donation: an integrative review. Transplantation 2012;93:1196-211. ${ }^{6}$

Irving MJ, Tong A, Jan S, Cass A, Rose J, Chadban S, et al. Factors that influence the decision to be an organ donor: a systematic review of the qualitative literature. Nephrology Dialysis Transplantation 2012;27:2526-33. ${ }^{7}$

Other relevant reviews and recent articles include:

Curtis RMK, Manara AR, Madden S, Brown C, Duncalf S, Harvey D, et al. Validation of the factors influencing family consent for organ donation in the UK. Anaesthesia 2021:anae.15485. ${ }^{8}$

López JS, Soria-Oliver M, Aramayona B, García-Sánchez R, Martínez JM, Martín MJ. An Integrated Psychosocial Model of Relatives' Decision About Deceased Organ Donation (IMROD): Joining Pieces of the Puzzle. Front Psychol 2018;9.9

López JS, Martínez JM, Soria-Oliver M, Aramayona B, García-Sánchez R, Martín MJ, et al. Bereaved relatives' decision about deceased organ donation: An integrated psycho-social study conducted in Spain. Social Science \& Medicine 2018;205:37-47. ${ }^{10}$

Chandler JA, Connors M, Holland G, Shemie SD. "Effective" Requesting: A Scoping Review of the Literature on Asking Families to Consent to Organ and Tissue Donation. Transplantation 2017;101:S1-16. ${ }^{11}$

Shah SK, Kasper K, Miller FG. A narrative review of the empirical evidence on public attitudes on brain death and vital organ transplantation: the need for better data to inform policy. Journal of Medical Ethics; London 2015;41. ${ }^{12}$

Sharp C, Randhawa G. Altruism, gift giving and reciprocity in organ donation: A review of cultural perspectives and challenges of the concepts. Transplantation Reviews 2014;28:163-8. 13

Siminoff LA, Agyemang AA, Traino HM. Consent to organ donation: a review. Progress in Transplantation 2013;23:99-104. ${ }^{14}$

After mentioning the lack of evidence as "one of the main reasons for the families' refusal to consent", the authors write: "To overcome this issue, improvements should be made in documenting potential donors' consent in organ donation registries." This conclusion does not necessarily follow or only partially. There are several other means to address family refusal rates, on the one hand, and the lack of knowledge issue, on the other. These means include mass media campaigns, targeted educational campaigns, the presence of a Specialist Nurse for Organ Donation (SNOD) as it is done in the UK, extensive training of transplant coordinators for the family interview as it is done in Spain, financial incentives to donation, prioritization programmes as it is done in Israel, etc. Some countries (e.g. Germany) with much lower family refusal rates than Saudi Arabia, do not have an organ donation registry but only an organ donor card. Other countries (e.g. Spain) with very low family refusal rates, do not have any registry at all (except for living wills that are barely used in practice for registering organ donation preferences) nor any official organ donor card. Fostering communication about organ donation among relatives and training the medical staff to conduct the family interview are alternative ways to increase family knowledge without requiring the registration or documentation of individual preferences. 
In the next paragraph, the article says: "There are three known methods of consent when registering to become a donor upon death: informed consent (opt-in system), mandated choice and presumed consent (opt-out system)." This wording is confusing. First, the opt-in system is not based on informed consent but only on explicit or expressed consent. Second, although the opt-out system is compatible with a registry of refusals, presumed consent only applies when no registering has taken place. Third, it is important to differentiate the models of individual consent (informed, presumed) and consent policies (opt-in, opt-out, mandated choice) from the means available to individuals to express their consent or refusal to donate. Some countries have registries, others don't, regardless of their consent policy.

The article then states its main objective: "This paper aims to analyze the different types of consent systems to address the issue of the high rate of family refusal. The study offers some important insights that will aid decision-makers in selecting an alternative that is more likely to reduce the shortage of organs."

This objective presupposes that there is a causal relationship between the consent systems and the rates of family refusal. I would recommend the authors provide references or data to support such an assumption. I ignore whether this is the case or not and whether there is at least a correlation between the two. I am really curious about it. By looking at the Global Observatory on Donation and Transplantation's Newsletter Transplant 2017, which provides data on family refusal in many countries throughout the world, I fail prima facie to see any trend that may be related to the consent systems in place.

With regard to the article's proposal of a mandated choice policy, it is true that if registering a preference in favour or against organ donation was mandatory in the country, this would likely increase the registration rates and decrease the families' lack of knowledge about their loved one's wishes. As a consequence, the number of family refusals caused by this lack of knowledge would also likely decrease. Question is: first, is this the best way to increase organ donation rates and, second, how many family refusals are actually caused by lack of knowledge in Saudi Arabia?

To answer these questions, it would be good to give some perspective. According to the Global Observatory on Donation and Transplantation, Saudi Arabia had a deceased organ donation rate of 3.3 pmp in 2019 and 1.9 pmp in 2020, which is relatively low although not in the lower end of the ranking. In 2017, according to the same source, Saudi Arabia had a population of $32.2 \mathrm{M}$ and a total of 92 deceased donors, that is, a rate of 2.9 donors pmp; 333 family interviews were conducted asking for authorisation, out of which 230 (69\%) refused. The article mentions that, according to a 2009 study of Saudi University students, "about $70 \%$ of participants are willing to become donors". If this figure was representative of the general population, if all individuals had registered their wishes, if all families of those willing to donate authorised organ procurement, and if all potential donors were eventually converted into actual donors, the total number of donors in 2017 would have been $92+(333 \times 70 \%)=325$, increasing the donors rate to $10 \%$ which is much better (comparable to that of Germany that same year). [Another study (Alnasyan et al. 2019) also cited in the article but whose figures on willingness to donate are not mentioned by the article says that $77.7 \%$ of the general public expressed a willingness to donate, although $29.1 \%$ were willing to donate only to their relatives]

The problem is that we don't know how likely is such a scenario. There are no data provided in the 
article regarding how many of the family refusals were caused by lack of knowledge or by other reasons such as those cited in Palmer 2012: Not wishing for surgery to the body/having concerns regarding disfigurement; Feelings that the patient had suffered enough; Disagreements among the family group; Religious/cultural reasons; Dissatisfaction with healthcare staff and process; Concerns over delay to funeral/burial process; Unable to accept death, or lack of understanding of brain death; Concerns regarding the integrity of process e.g. unfair organ allocation of organs and organ selling; Relatives deciding themselves that organs would not be suitable; Longstanding negative views on organ donation; Relatives were emotionally exhausted.

Actually, the article itself mentions that some unknown proportion of the family refusals may not be caused by lack of knowledge: "It is important to note that, under the current policy, families still have the right to veto that decision despite their loved one's consent to become a donor." Also: "In many cases, the family trumps an individual's autonomy (Al-Shahri, 2002)" The reference here cited (Al-Shahri, 2002) says "In Saudi culture, the authority of the family overrules the individuals' autonomy. Decisions taken by patients can often be altered according to the views of the family". I am thus curious to know the proportion of families who veto the deceased's consent as well as their reasons to do so, because this is not caused by lack of knowledge of the deceased's wishes, and some of the families who do lack knowledge may share the same reasons to refuse as those who don't.

\section{Is the discussion on the implications clearly and accurately presented and does it cite the current literature?}

The discussion on the implications is quite clear but it lacks accuracy and it does not cite enough updated and relevant literature.

For example, the authors mention that "According to a news article, the number of registered donors increased from 20,000 to 200,000 , which is a $115 \%$ increase after the launch of the donor registration feature". This is a ten-fold increase and definitely not a $115 \%$ increase. Something is wrong. I checked (using an automated translator) the news article cited here and it seems that these figures are actually mentioned. I failed to see any sources cited in the news article. This tells me that this news article is not reliable and thus it is not worth citing in a scientific article. Anyway, even if the 20,000 to 200,000 increase in registrations was true, compared to more than $34 \mathrm{M}$ inhabitants in 2021, this represents only $0.6 \%$ of the total population. This is much better, but still anecdotal.

Another example. The article claims that "after adopting a hard opt-out policy in Austria, the rate of donations quadrupled within eight years (Zink et al., 2005). On the other hand, a soft approach to the policy did not impact donation rates in Spain, which indicates that a hard opt-out policy could be more effective." There are several problems here. First, the reference cited with regard to Austria does not provide any evidence for the claim but cites two other sources, one of which ${ }^{15}$ makes this claim without any evidence or references provided. This claim may be true or it may not, but the reference cited here is not sufficient to support the claim. Second, with regard to Spain, the policy is soft in clinical practice but hard according to the law. Third, what did impact donation rates in Spain was not the implementation of an opt-out policy in 1979, but the creation of the National Transplant Organisation (ONT) in 1989. Fourth, it is odd to claim that a hard optout policy (such as in Austria) could be more effective than a soft opt-out policy (such as in Spain) considering that Spain has a much higher donation rate (49.6 pmp in 2019) than Austria (23.4 pmp 
in 2019) according to the GODT. Fifth, several studies, including systematic reviews, have explored the impact of presumed consent policies. They should be cited.

One more example. The article mentions "a study in the Netherlands, a country that adopted a mandated choice, concluded that this system generated more registered donors than both informed and presumed consent systems (Van Dalen \& Henkens, 2014)." First, the Netherlands had not adopted a mandated choice policy but an opt-in system (as the authors of the cited study clearly state in their article). Second, the Netherlands have recently implemented an opt-out system. Third, the cited study does not assess the actual performance of a mandated choice system in the country but compares, in an experimental setting using counterfactuals, whether people would register as donors (hypothetically) if they moved to a region with presumed consent, explicit consent, or mandated choice. Fourth, the results from this study show that people would be more willing to register as donors under a mandated choice system (66\%), but this result is only 4 points higher than presumed consent (62\%) and many more people would also refuse to donate under a mandated choice system (34\%) than under a presumed consent system (18\%). In other words, mandated choice would increase donors by $4 \%$ and non-donors by $16 \%$ when compared to presumed consent.

\section{Are the recommendations made clear, balanced, and justified on the basis of the presented arguments?}

The first recommendation is changing the method of obtaining consent from opt-in to mandated choice. Considering the comments above, it is not sufficiently justified. The authors may want to look at a similar recommendation made in other countries, such as a law proposal (unsuccessful) made by members of the German Parliament (see http://dip21.bundestag.de/dip21/btd/19/110/1911087.pdf, text in German), as well as the report on organ donation by the Swiss National Human Medical Ethics Commission (see https://www.nekcne.admin.ch/inhalte/Themen/Stellungnahmen/fr/NEK-Stellungnahme_Organspende_FR.pdf, text in French).

The second recommendation refers to modifying the Tawakkalna App. The proposed modifications may be useful, provided that more people register their organ donation preferences in the app.

The third recommendation or part of it is sensible: "more research dedicated to assessing the feasibility of implementing a new consent system", as well as "understanding the current Saudi context" to predict [I would say, estimate] its success.

\section{References}

1. Kentish-Barnes N, Siminoff LA, Walker W, Urbanski M, et al.: A narrative review of family members' experience of organ donation request after brain death in the critical care setting. Intensive Care Med. 45 (3): 331-342 PubMed Abstract | Publisher Full Text

2. Miller C, Breakwell R: What factors influence a family's decision to agree to organ donation? A critical literature review.London J Prim Care (Abingdon). 2018; 10 (4): 103-107 PubMed Abstract | Publisher Full Text

3. T M, N A, MS N, RA R, et al.: FAMILY DECISION-MAKING ABOUT ORGAN DONATION: A SYSTEMATIC REVIEW. Journal of Health and Translational Medicine. 2015; 18 (1): 1-4 Publisher Full Text 
4. Ralph A, Chapman JR, Gillis J, Craig JC, et al.: Family perspectives on deceased organ donation: thematic synthesis of qualitative studies.Am J Transplant. 2014; 14 (4): 923-35 PubMed Abstract | Publisher Full Text

5. Walker W, Broderick A, Sque M: Factors influencing bereaved families' decisions about organ donation: an integrative literature review.West J Nurs Res. 2013; 35 (10): 1339-59 PubMed Abstract | Publisher Full Text

6. de Groot J, Vernooij-Dassen M, Hoedemaekers C, Hoitsma A, et al.: Decision making by relatives about brain death organ donation: an integrative review.Transplantation. 2012; 93 (12): 1196-211

PubMed Abstract | Publisher Full Text

7. Irving MJ, Tong A, Jan S, Cass A, et al.: Factors that influence the decision to be an organ donor: a systematic review of the qualitative literature.Nephrol Dial Transplant. 2012; 27 (6): 2526-33

PubMed Abstract | Publisher Full Text

8. Curtis RMK, Manara AR, Madden S, Brown C, et al.: Validation of the factors influencing family consent for organ donation in the UK.Anaesthesia. 76 (12): 1625-1634 PubMed Abstract | Publisher Full Text

9. López J, Soria-Oliver M, Aramayona B, García-Sánchez R, et al.: An Integrated Psychosocial Model of Relatives' Decision About Deceased Organ Donation (IMROD): Joining Pieces of the Puzzle. Frontiers in Psychology. 2018; 9. Publisher Full Text

10. López JS, Martínez JM, Soria-Oliver M, Aramayona B, et al.: Bereaved relatives' decision about deceased organ donation: An integrated psycho-social study conducted in Spain.Soc Sci Med. 205:

37-47 PubMed Abstract | Publisher Full Text

11. Chandler JA, Connors M, Holland G, Shemie SD: "Effective" Requesting: A Scoping Review of the Literature on Asking Families to Consent to Organ and Tissue Donation.Transplantation. 101 (5S Suppl 1): S1-S16 PubMed Abstract | Publisher Full Text

12. Shah SK, Kasper K, Miller FG: A narrative review of the empirical evidence on public attitudes on brain death and vital organ transplantation: the need for better data to inform policy.J Med Ethics. 2015; 41 (4): 291-6 PubMed Abstract | Publisher Full Text

13. Sharp C, Randhawa G: Altruism, gift giving and reciprocity in organ donation: a review of cultural perspectives and challenges of the concepts.Transplant Rev (Orlando). 2014; 28 (4): 163-8 PubMed Abstract | Publisher Full Text

14. Siminoff LA, Agyemang AA, Traino HM: Consent to organ donation: a review.Prog Transplant. 2013; 23 (1): 99-104 PubMed Abstract | Publisher Full Text

15. Gundle K: Presumed consent: an international comparison and possibilities for change in the United States.Camb Q Healthc Ethics. 2005; 14 (1): 113-8 PubMed Abstract | Publisher Full Text

Does the paper provide a comprehensive overview of the policy and the context of its implementation in a way which is accessible to a general reader?

No

Is the discussion on the implications clearly and accurately presented and does it cite the current literature?

No

Are the recommendations made clear, balanced, and justified on the basis of the presented arguments?

Partly 
Competing Interests: No competing interests were disclosed.

Reviewer Expertise: Ethics of organ donation; Health policy

I confirm that I have read this submission and believe that I have an appropriate level of expertise to state that I do not consider it to be of an acceptable scientific standard, for reasons outlined above.

Author Response 05 Jul 2022

Deema AL Shawan, Imam Abdulrahman Bin Faisal University, Dammam, Saudi Arabia

Dear Dr. Molina-Pérez,

We thank you for taking the time to provide constructive feedback on our policy brief. We have incorporated the suggested edits to reflect your valuable input into our resubmitted manuscript. Additionally, we have a point-by-point response below:

Comment: "This second claim is based on Palmer 2012. Although this reference appears to be a good review of the literature, it has not been peer-reviewed. In addition, it is also relatively outdated (meaning that other reviews have been conducted more recently) and the studies reviewed were conducted mostly in English speaking Western countries: the United States, the United Kingdom, Australia, which means that their conclusions may not necessarily be extensible to other cultural contexts such as Saudi Arabia."

Response: We agree, and to support the claim, we have replaced the (Palmer, 2012) article with one of your suggested sources

Comment: "In other words, although it may be true that lack of knowledge by the family is, in these countries, one of the main reasons for their refusal, there is no guarantee that the same conclusion holds in other countries, especially when these"

"Since the argument of the article is based on the claim that family refusals are mainly caused by the family's lack of knowledge of the potential donor wishes (which could be addressed, according to the authors, by a mandated choice policy), stronger evidence is needed to support this claim, especially in the context of Saudi Arabia. In other words, authors should provide more updated and compelling evidence that this claim is true-or, at the very least, that it may be true in their country-before proposing a policy to address it. "

Response: Due to the lack of up-to-date evidence in Saudi Arabia we have added evidence from another country as well as a survey about the Saudi publics acceptance towards this policy. Additionally, we have edited the recommendation to investigating it as a potential viable and feasible solution given the country's culture.

Comment: "There are several other means to address family refusal rates, on the one hand, and the lack of knowledge issue, on the other. These means include mass media campaigns, targeted educational campaigns, the presence of a Specialist Nurse for Organ Donation (SNOD) as it is done in the UK, extensive training of transplant coordinators for 
the family interview as it is done in Spain, financial incentives to donation, prioritization programmes"

Response: We have acknowledged that there is a need to combine the proposed consent system with other methods to ensure it's effectiveness to increase its effectiveness in reducing the shortage of organs

Comment: "In the next paragraph, the article says: "There are three known methods of consent when registering to become a donor upon death: informed consent (opt-in system), mandated choice and presumed consent (opt-out system)." This wording is confusing."

Response: Thank you for pointing that out, we have corrected the wording accordingly.

Comment: "The article then states its main objective: "This paper aims to analyze the different types of consent systems to address the issue of the high rate of family refusal. The study offers some important insights that will aid decision-makers in selecting an alternative that is more likely to reduce the shortage of organs. This objective presupposes that there is a causal relationship between the consent systems and the rates of family refusal. I would recommend the authors provide references or data to support such an assumption. I ignore whether this is the case or not and whether there is at least a correlation between the two. I am really curious about it."

Response: We appreciate the suggestion, even though we have not included a study that discusses the overall impact of consent systems on organ donation rates. We have included evidence on the effectiveness of each of the types of consent mechanisms throughout the policy brief.

Comment: "Question is: first, is this the best way to increase organ donation rates and, second, how many family refusals are actually caused by lack of knowledge in Saudi Arabia?"

Response: Thank you for your comment to clarify, the article does not claim that this is the best or the only approach but it is one of the main factors identified and it is also one of the most understudied. Additionally, as stated previously, we recommended the incorporation of other interventions, such as educational campaigns, since changing the method of consent alone may not be as effective (justification and evidence were included in the manuscript). As for the second question, there are no up to date published statistics on the exact number of family refusal due to the lack of knowledge. Nevertheless, we have included a study by (Kentish-Barnes et al., 2019; Walker et al., 2013) that states that one of the causes of family refusal is not knowing their loved ones' wish to donate.

Comment: "For example, the authors mention that "According to a news article, the number of registered donors increased from 20,000 to 200,000 , which is a $115 \%$ increase after the launch of the donor registration feature". This is a ten-fold increase and definitely not a $115 \%$ increase. Something is wrong. I checked (using an automated translator) the news article cited here and it seems that these figures are actually mentioned. I failed to see any sources cited in the news article. This tells me that this news article is not reliable and 
thus it is not worth citing in a scientific article. Anyway, even if the 20,000 to 200,000 increase in registrations was true, compared to more than $34 \mathrm{M}$ inhabitants in 2021, this represents only $0.6 \%$ of the total population. This is much better, but still anecdotal.

Response: The article was replaced with on of the few reliable published sources. The information was also edited to demonstrate the rapid registrations after the launch of the app instead of the claim that the app has increased the number of donors due to the lack of evidence. This was to further support the objective of the paper which is to urge decisionmakers to take the opportunity to optimize the newly launched feature in the app in the future

Comment: "the reference cited with regard to Austria does not provide any evidence for the claim but cites two other sources, one of which ${ }^{15}$ makes this claim without any evidence or references provided. This claim may be true or it may not, but the reference cited here is not sufficient to support the claim."

"Fourth, it is odd to claim that a hard opt-out policy (such as in Austria) could be more effective than a soft opt-out policy (such as in Spain) considering that Spain has a much higher donation rate (49.6 pmp in 2019) than Austria (23.4 pmp in 2019) according to the GODT.

"several studies, including systematic reviews, have explored the impact of presumed consent policies. They should be cited."

Response: As recommended, the study was replaced by by a systematic review that investigated the impact of the presumed consent policy in different countries. The other other findings were also corrected as suggested.

Comment: "the Netherlands had $\underline{\text { not }}$ adopted a mandated choice policy but an opt-in system “

"Third, the cited study does not assess the actual performance of a mandated choice system in the country but compares, in an experimental setting using counterfactuals, whether people would register as donors (hypothetically) if they moved to a region with presumed consent, explicit consent, or mandated choice."

"the results from this study show that people would be more willing to register as donors under a mandated choice system (66\%), but this result is only 4 points higher than presumed consent (62\%) and many more people would also refuse to donate under a mandated choice system (34\%) than under a presumed consent system (18\%). In other words, mandated choice would increase donors by $4 \%$ and non-donors by $16 \%$ when compared to presumed consent.

Response: We thank you for the corrections and suggestions, the sources were updated.

We look forward to hearing from you regarding our submission and to respond to any further inquiries and comments you may have. 
Sincerely,

Dr. Deema S. Al Shawan

Competing Interests: No competing interests were disclosed.

The benefits of publishing with F1000Research:

- Your article is published within days, with no editorial bias

- You can publish traditional articles, null/negative results, case reports, data notes and more

- The peer review process is transparent and collaborative

- Your article is indexed in PubMed after passing peer review

- Dedicated customer support at every stage

For pre-submission enquiries, contact research@f1000.com 